\title{
Human resource management challenges facing local NGOs
}

\author{
Rehema C. Batti \\ School of Management, Atlantic International University, 900 Fort Street Mall 40 Honolulu, Hawaii 96813, USA
}

Email address:

rehemabatti2012@gmail.com

To cite this article:

Rehema C. Batti. Human Resource Management Challenges Facing Local NGOs. Humanities and Social Sciences. Vol. 2, No. 4, 2014, pp. 87-95. doi: 10.11648/j.hss.20140204.11

\begin{abstract}
Partnership with local NGOs has become an important feature in the development sector. Therefore the management of human resources in local NGOs is crucial as it contributes to the performance and sustainability of the organizations. However many local NGOs face diverse challenges in the area of human resource management. Local NGOs have inadequate HR management procedures in the organization and this affects the employee's work experiences and overall performance at individual and organizational level. Many local NGOs due to the size of the organization and scope do not have a human resource (HR) unit or a human resource manager and therefore they appoint staff to oversee staff issues who often do not have the required human resource skills and competencies to manage the employees. Another area that is challenging local NGOs is the fact that many depend on donor funds that are tied to funding cycles that are short term in nature. This affects the NGOs human resource capacity in terms of the number and type of staff to recruit and employment duration. The mentorship of management and board members in human resource management could be one way to improve human resource competence in these organizations. This paper seeks to highlight human resource management challenges local NGOs encounter and the importance of considering HRM as a strategic process that can contribute to sustaining an organization's performance.
\end{abstract}

Keywords: Human Resource Management in NGOs, Challenges in Human Resource, Human Resource Management

\section{Introduction}

People are an important aspect in all social organizations and from the perspective of the organization, people are resources and organizations cannot exist without them. The importance of people is immense as they support development of the organization's objectives and achievements for which NGOs are recognized for.

Organisations are becoming aware that human resources are an important asset that can provide sustained competitive advantages. However adoption of effective human resource management (HRM) practices in many local Non Govermental organizations (NGOs) is often low in the list of management priority.

Successful NGOs are those that recognize the significance of the human element on organizational success and emphasize on their development, satisfaction, commitment and motivation in order to attain desired objectives.

Local (NGOs) often do not realize the importance of effective management of human resources to the well being of the organization and hence do not invest adequate time or resources to build their capacity in necessary human resource competencies.

The lack of attention on the management of human resource is one of the factor standing between success and failure in many local NGOs in developing countries. According to Ulah \& Yasmin (2013:2) in the age of competitiveness organizations cannot afford to bear the loss of potential human resource.

Sustainable development of an organization depends upon effective management of its human resources. However little attention has been paid on the adoption of effective human resource management practices in many local NGOs in the development sector yet it is an aspect that can transform organization staff into a productive and motivated workforce capable of improving organization services.

Changing expectations of stakeholders, growth in internet 
usage and rapid development of e-commerce is pressurizing organizations in every sector to make improvements in service delivery and human resource effectiveness.

The contribution of people to an organization is unpredictable, unique and has potential for further development because people have beliefs, values and different levels of experience that can be tapped for both individual and organizational benefit.

How effectively local NGOs operate and achieve their goals depends largely on how professionally and productively people are managed. Employees are required to understand the future of the organisation and their own future in the organisation this helps triggers commitment and hence sustained productivity.

Hence it is right to say that local NGOs are dependent on the contribution of the human resource that exists within the organization and as an organization they have no choice but to proactively identify and explore opportunities that will assist in building their competency in managing employees.

\section{Overview of Human Resource Management Definition and Practice}

\subsection{Definition of Human Resource Management}

Human resource management is a core management function in any type of organization. It creates the most crucial condition for organizational performance.

Human resource management is a process that assists organizations recruit, select and develop staff within the organization. According to Stanley and Albin (2013:209) ${ }^{1}$ they define human resource management as a management function within organizations concerned with people and their relationships at work.

The foundation of HRM is that everyone in the organization is capable and has the ability to perform and it's the sole responsibility of management to put in place system and structures to motivate performance.

One of the purpose of the HRM is to build an organisation with the 'right persons', in the 'right positions' and at the 'right time'. The purpose of a Human resource framework is to guide organizations to achieve this objective. The issues revolving around managing human resources can be split into two:

\subsubsection{Strategic HRM}

Here the focus is on the system as a whole. It targets long-term issues as concerns organization structure, quality of service, organizational culture and commitment that exist and then looks into linking resources with future vision.

\subsubsection{Operational HRM}

This deals with issues at the individual level, such as

\footnotetext{
${ }^{1}$ Stanley Vincent, Albin Joseph (2013) Challenges for human resource experts in Global scenerio. International Journal of advancement in Research and Technology. Vol 2, Issue 4,April 2013.SciResPub.
}

career planning and activities. Examples of include employment applications processing, filling open positions, training supervisors, addressing safety and health problems and handling salaries.

The HR framework enables organizations to manage their human resources effectively and tries to link human resources with the organizations strategic goals. This also involves taking into considerations internal and external factors that affect human resources which influence changes in strategies and practice in human resource management.

\subsection{Human Resource Theories}

Human resource management principles and techniques are drawn from various theories found in different disciplines.. According to Michael Armstrong (2012:6-7 $)^{2}$ the following are the theories that guide HRM:

\subsubsection{Resource Dependency Theory}

Scarcities of resources determine policies and procedures to be adopted by organisations. Employees are scarce resources, which should be carefully managed.

\subsubsection{Competitive Advantage Theory}

Organisations should capitalize on competitive advantage it has over other organisations. An employee is a rare resource, immutable, non-substitutable, and valuable In order to gain from competitive advantage, there should be creation and support of organizational culture that ensures effective management of training and performance management functions.

\subsubsection{Institutional Theory}

Organizational norms, values, attitudes and myths are the sources of organizational failure or success. These need be coordinated and managed to ensure effectiveness.

\subsubsection{Agency Theory}

In this theory the employer and employee have a principal-agent relationship. As there may be disagreement between the two, legal implications have to be carefully considered and, if possible, litigation should be avoided.

\subsubsection{General Systems Theory}

Organisations are complex systems. Human resource management is a sub system. Failure/success of each component will have overreaching impact to the organisation.

\subsubsection{Human Capital Theory}

It is an economic approach which describes people are valuable assets. This emphasizes investing in people as one does with other organizational assets.

\subsubsection{Organization Life Cycle Theory}

Organisations are seen to grow in different stages. They

\footnotetext{
2 Armstrong Michael (2012), Armstrong's Handbook of Human Resource Management practice.(12 ${ }^{\text {th }}$ edition $)$ UK. Ashford Colour Press
} 
start, grow, mature, decline and revive. This theory links the human resource management according to the stage of growth of the organisation.

\subsubsection{Role Behavior Theory}

The means used by an organisation to send role information determines role response (behavior).Human resource management should focus on improving the role information for employees.

\subsubsection{Organizational Change Theory}

Organisations pass through different forms, levels of quality, and states over time. Human resource management should ensure congruence between stated goals, changes, and performance.

\subsubsection{Transaction Cost Theory}

It is an economic point of view of governance structures in business transactions. It considers costs of establishment, monitoring, evaluation, and enforcement of exchanges (contracts). Since managers have limited information for decision making (bounded rationality) before transactions, there must be measures to reduce risks. Managers should seek opportunities to be used by employees. Human resource management should minimize loopholes in employment relationships like reviewing contracts, monitor, and ensure compliance to set objectives, targets and standards.

\subsubsection{Strategic Contingency Theory}

Organisations have several strategic typologies to adopt. The choice of typology depends on organizational environment. Human resource management should depend on a particular typology chosen.

\subsubsection{Organizational Learning Theory}

The success of an organisation depends on the ability of the employees to learn. Human resource management should ensure continuous learning so that an employees' prior knowledge facilitates learning and gives them the ability to apply new related learning.

\subsection{Human Resource Management as a Strategic Function within an Organization}

Globalisation has increased competition among organizations and organizations are tasked on how to accomplish competitive advantage through people. The rise of globalization, has affected organizations of all sizes as this has meant they have to interact with stakeholders from diverse nationalities, religions, cultures, language and social backgrounds. This requires the HR role to embrace a global perspective and ensure that policies and procedures are in line with the global market.

Globalization is also putting pressure on organization to focus on employee professional development. This involves providing employees opportunities to achieve their career-related goals and this also has meant organizations have to factor this in their HR management.
As organizations continue to grow across a global environment, they strive to find new and effective methods through which they can increase their competitive advantage in their sectors of operation. According to Ullah \& Yasmin $(2013: 3)^{3}$ the appropriate use of human resources develops the performance of an organization.

Therefore the HR role is transforming into a more strategic function with an indepth understanding of the organization's mission and having the ability to advise management and leadership on key decisions and policies.

According to Michael Armstrong (2011:6) ${ }^{4}$ SHRM is the interface between HRM and SHRM. Strategic HRM is a process that enables an organization to systematically link employees and organizational strategic focus. The need for strategic HRM has increased due to increase in globalization of business which has caused the rise of a competitive environment where the only way to remain relevant is to build and improve the laborforce.

The function of Human Resource is divided into transactional and strategic tasks. Transactional tasks include recruitment, training, dealing with people issues, legal compliance and employee services while strategic tasks revolve around achievement of the organization goals and values and involve forward looking HR strategies. (Armstrong 2011:72). ${ }^{5}$

\subsubsection{Definition and the concept of Strategic-HRM}

The development of the term 'strategic HRM' (SHRM) is linked to 'integration' of HRM into the strategy of the organization and 'adaptation' of HRM within the organisation. The field of strategic HRM is still developing and it tries to systematically link people and integrate HRM strategies into organization strategies.

Armstrong (2008:35) ${ }^{6}$ elaborates that the aim of strategic HRM is to develop capability within the organization to ensure it has skilled and well motivated employees to achieve sustained competitive advantage so as to become flexible than their competitors.

The focus is on aligning of HR practices, policies and programs with strategic plans of the organization. The integration between HRM and an organization's strategic plan is seen to eventually contribute to effective management of human resources and improve the organization's performance. Strategic HRM has two core aspects which include the following:

a) The integration of HRM into the organization's strategy

b) The devolvement of HRM to line managers

\footnotetext{
${ }^{3}$ Ullah, Ifran and Yasmin Robina (2013) The influence of human resource practices on internal customer satisfaction and organization effectives. Journal of internet banking and commerce. August 2013, Volume 18, Issue 2:1-28. ${ }^{4}$ Armstrong Michael (2011), Armstrong's handbook of strategic HRM. $5^{\text {th }}$ edition, London, Kogan Page. E-book collection(EBSCO host) Ipswich MA accessed 10/April 2014

5 Ibid (2011:72)

${ }^{6}$ Armstrong Michael (2008) Strategic Human Resource Management: A guide to action. London. Kogan Page
} 


\section{Challenges facing local NGOs in Human Resource Management}

The objective of this assessment was to identify and understand the human resource challenges that face local NGOs in the development sector and to highlight possible solutions to address the problems. The assessment used focus group discussions and interviews with staff of selected local NGOs in the development sector to get the information presented.

The following are the human resource problems identified within the local NGOs;

\subsubsection{Recruitment and Retention of Competant Staff}

Many of the sampled local NGOs work with a project orientation focus which means there is low priority for investing in nurturing human resource capacities and staff retention measures due to their short term nature of the projects.

Some organizations are not able to have the right employees at the right time and place. When they recruit the staff they face the challenge of retaining them to the end of the project phase as staff leave before the termination of the project.

This dynamism experienced in project-oriented organizations is a great challenge as staff turnovers are often high and erratic and this destabilizes programming and eventually the performance of the organization.

Some of the geographical areas where the NGOs operate are inaccessible or remote and it becomes difficult to attract staff to work in these sites and they are forced to rely on temporary staff or unqualified staff to fill the positions.

\subsubsection{Inadequate Human Resource Policies or Procedures}

Some of the local NGOs sampled do not have in place HR guidelines that support staff management. Where they exist they are not utilized and are instead used as tools to get donor funds.

Much of the staffing management issues are done in an adhoc manner and it is never clear what the employee is expected to do at a given time. In some organizations the policies that exist are not aligned with government labour policies. For example the government has a policy that a nursing mother will be given three months leave with pay but in some organizations they gave either one month or the policy was not included at all.

Some NGOs did not have contracts, job descriptions or letter of appointments for the staff. It is therefore difficult to get records of when staff were employed, what they are entitled to, length of contract and what their responsibilities were.

In some organizations because they did not have contracts some of them went without pay during some months, were never given leave breaks from work, were deducted some of their pay for some unexplained expenses by management.

\subsubsection{Lack of Capacity to Manage a Diversity of Work Force}

A challenge facing local NGOs is how to manage diverse groups that exist in the workforce to ensure they are committed to the organization's mission. Many face challenges in the motivation of people of diverse age and gender and many of the organization still use outdated methods to manage the staff.

For example there is rise in the recruitment of younger better "educated" staff and this has contributed to tensions between the older "experienced" staff. Therefore there was lack of delegation of work in a clear and systematic way due to conflicting approaches to work and suspicion among the two groups.

Sometimes the lack of educated and skilled labour force within a location affected recruitment as some organizations had to hire part time staff or work with volunteers yet the organizations did not have relevant policies to engage with the groups effectively.

In other instances it was a challenge especially where they had those who were employed /appointed by the community and those who used the formal system of recruitment.

\subsubsection{Mismatching of Employee Qualifications with Jobs or Positions}

In some organization a staff was placed in a position that they did not have the required competency or the skills to perform the tasks adequately. For example a staff trained in procurement was recruited as an accountant or an engineer as a program coordinator in a health project.

In other scenarios those holding management positions did not have the relevant skills or knowledge to support the other staff they supervised. These scenarios resulted to poor performance in the organizations as the staff was not able to undertake their duties effectively.

Local NGOs need to understand that they cannot succeed if employees perceive they are underutilized or are utilized at the wrong time or in the wrong position.

\subsubsection{Inadequate HR Management Skills among Supervisors}

The size of many of the local organizations is small. In an organization of 3-10 organizations many do not have a HR unit or a HR manager and this may not be a practical idea due also to the cost implications.

The HR function is therefore in these NGOs is handled by either a project manager or another staff who may not have the necessary HR skills and this creates conflicts in management.

This lack of HR skills affects the day-to-day management of the organization and has in some instances led to conflicts over responsibilities between management and staff over who should implement what activities.

\subsubsection{Organization Program Strategies Affect Staffing}

Many local NGOs are entering into alliances and partnerships with either National or international organizations, business or government, and these engagements require them to recruit or restructure their human resources to exploit the new opportunities. This 
means staff appointments are sometimes project based, contractual and for specified periods.

In some organizations there exist 2-3 projects supported by different donors who may unfortunately implement different salary schemes and work practices and this creates conflicts within the organization and creates management challenges.

Where organizations are in partnership with a donor agency and the donor does not provide funds to hire additional staff then the existing staff are sometimes required to take up multiple roles without having the necessary skills required. This causes an increase in workload, stress, dissatisfaction among staff and eventually causes underperformance of the entire organization.

\subsubsection{Inability to Offer and Provide Competitive Employee Incentives and Benefits}

This issue is most challenging in NGOs because offering competitive benefits to employees has high cost implications and local NGOs do not have the financial resources to do so. The salaries or incentives provided are dependent on the donor funds received or the income generated through an enterprise activity undertaken by the organization.

This sometimes impacts heavily on the staff morale and performance within these organizations.

\subsubsection{Inadequate Performance Management Systems}

Managers and employees are required to develop performance targets and output that define individual tasks. However many staff and management acknowledged that this process does not exist in their organizations. There were no tools or mechanisms to support staff appraisals and hence it meant that it was not easy to track staff performance.

Yet some of the reasons management would give for firing a staff would be due to poor performance but with further inquiry how that was determined there is no documented evidence of the "poor performance".

Managers who did not set work targets and this de-motivated staff. Many staff feel frustrated about the lack of constructive feedback on their performance often because it is unclear what is expected of them.

Many local NGOs have not embraced a performance culture within their organizations. This results in low or poor performance in terms of achievements of the planned organizational mandates.

\subsubsection{Inadequate Career Development Opportunities}

Another challenge facing staff in local NGOs is the lack of career enhancement opportunities. This would involve continuously working towards creating new job opportunities and supporting staff to develop within the organization to keep up the morale.

In the past organizations equipped employees to fulfill organizational requirements through training and developmental interventions. However the scope and cost of training and development has risen with the reality of trained employees quitting before making significant contribution to the organization after the training and therefore many organizations do not plan for this.

In situation where training opportunities were available o the relevant staff was not given opportunity to attend and instead another staff is sent for training or the supervisors attend the trainings yet they are not directly involved in project implementation activities.

In project-oriented organizations there is no certainty of growing in one's career as the funding duration is normally short term and funds or opportunities to support development of human resources capacity are normally few or not available.

\subsubsection{Difficulties in Maintaining Balance between Employee and Organization Needs}

Another challenge facing organizations is the alignment of employee expectations with the organization's strategic focus. Local NGOs constantly face the difficult task of trying to balance between employee concerns and organizational strategic and financial goals.

Employees perceived that their concerns and needs were not being addressed by the organizations and were overshadowed by the organization's need to please donors. Employees eventually lacked motivation to work towards fulfilling the organization's objectives or core mission.

There is also limited investment in people who have been around for long periods in the organisation to counter the sense of dissatisfaction and distancing from the vision.

\subsubsection{Lack Induction and Coaching Mechanisms for New Employees}

Many local NGOs made the assumption that the staff they recruited had the skills required to perform their duties. Yet many fail to realize that the staff recruited need to understand the organization mandates and projects for them to work effectively.

Many young people joining local NGOs felt that there is not enough mentoring or clear career direction, while at the same time there is a pressure to learn and deliver on the project outcomes.

Staff in some of the local NGOs felt their supervisors did not give them clear guidance about the day to day tasks required to perform their roles and this scenerio was made worse where there were no job descriptions. This resulted in supervisors setting unrealistic demands on the staff or the staff ended up not undertaking the tasks as required.

\subsubsection{Presence of Leadership Gaps/Crisis}

Many of the local NGOs face leadership crisis. Once a management position falls vacant, many of the organizations were seen to have difficulties in getting a replacement and there are instances when this position remains vacant for over a period of 6 months to one year.

There are also challenges faced when the founder members hold management positions within the organizations and they do not give opportunity or build the leadership capacity of other managers or staff within the organization.

Many local NGOs focus more on building their technical 
skills and knowledge but fail in planning for development of leadership or management structures. This aspect often is often not seen as a priority but many suffer the consequences of serious leadership vacuum in the organization.

\subsubsection{Inadequate or Clear Structures for Rewarding Performance}

Many staff felt the organizations did not reward or recognize staff for good or exemplary performance and sanctions against poor performers was something that many of the organizations failed to address or ignored. Some staff felt that as long as the staff was linked or perceived to be 'loyal' to management poorly performing staff would remain in service for long without any action being taken.

This caused tensions among those who felt they worked extra hard to contribute to achievement of organization objectives yet they were not recognized for their efforts.

It was noted that the criteria for allocation of benefits was not clear and was mostly associated with "loyalty" to management rather than performance.

\section{Recommendations}

Based on the listed challenges in managing human resources. Local NGOs in the development sector need to adopt a strategic focus in human resource management and replace the traditional forms.According to Khavul etal (2009:1) $)^{7} \mathrm{HRM}$ in small organizations is often ad hoc, and often a reflection of the backgrounds of founders and entrepreneurs.

I see there is a need for local NGOs to borrow and contextualize best and promising HRM practices used by the business sector to improve organizational HR management. This will address the issues that arise as a result of having adhoc HRM practices that are influenced by the founders of the local NGO or are not contextualizad to fit the context in which an organization operates.

The following are posible solutions that would be relevant if adopted and implemented to address the current challenges that local NGOs have in managing human resources.There is evidence that the earlier small organizations adopt HRM approaches and the extent to which they invest in the practices and people, have long-term impacts on organizational growth and survival. (Khavul etal 2009:2) ${ }^{8}$

\subsection{Develop Relevant (Context Based) Human Resource Guidelines or Policies}

Many of the local organization either lacked HR policies or a manual to guide management of employee or had

\footnotetext{
${ }^{7}$ Khavul, Susanna; Benson, George S.; and Datta, Deepak K. (2009) "Human Resource management and international new ventures from emerging," Frontiers of Entrepreneurship Research: Vol. 29: Iss. 18, Article1.Availableat:http://digitalknowledge.babson.edu/fer/vol29/iss18/1.acces ed on $23 / 4 / 2014$

${ }^{8} \operatorname{Ibid}(2009: 2)$
}

policies that were not aligned to the organizations context or government policies.

Where a manual existed it was not approved by management and therefore the guidelines were not implemented.

The organizations need to develop detailed HR polices that reflect the existing organizational environment and then go beyond developing the policies to institutionalize them.

\subsection{Development of HRM Plan Linked to Organization Strategic Focus}

Human resource planning is important for management of human resources in local NGOs. This process will ensure the NGOs have the human resource capacity required to achieve their organization's goals and deliver results effectively in the present and in the future.

Most of the local NGOs have financial and strategic plans that guide achievement of the organization's mission. However development of human resource plans is not a common organizational practice. A human resource plan will enable the organization identify and match staff with the relevant positions planned for within the organization and avoid uphazard recruitment of staff which is more often donor driven and not organization focused.

This will also address the issue of having many conflicting staffing structures due to having different donor supported projects and ensures alignment in the management of employees within different donor projects

Local NGOs although they have few staff should develop a HR plan to guide HR decisions that are focused and centred on the organization's vision and not necessarily on the donor.

\subsection{Develop Mechanisms That Support Identification, Development and Utilization of Staff Capacity}

Local NGOs need to develop structures and create opportunities that will fully utilize the potential of their employees. According to Shilpika (2012:612) ${ }^{9}$ the reality is that people are undervalued, not adequately trained, underutilized and poorly motivated in many organizations and consequently perform well below their true capability.

Many employees feel they are wasted and not given the opportunity to develop their capacity or use the knowledge they have gained in similar previous positions.

Local NGOs need to use different approaches in job design/redesign and placement so that they can adequately utilize their existing staff capacity.

Organizations need to employ talent management processes that involve instituting initiatives to utilize and develop capacity of personnel.

The local NGOs can develop simple human resource information database which they can use to record and store

\footnotetext{
${ }^{9}$ Shilpika Pandey (2012)Future trends in HRM ,VSRD International journal of business and management research Vol 2,No 12,Dec 2012.www.vrsdjournals.com
} 
data related to their employees. This will help in tracking the skills available that are not utilized and those that are lacking and need to be developed.

\subsection{Conduct Mentorship on HR Management for Board Members and Project Managers}

There is need for HR competency among project managers and board members within local NGOs. Many local NGO management level staff do not have skills in managing people. This leads to conflicts, underperformance and underutilization of employees.

Local NGOs should invest in providing basic HR skills to their management staff and this can be done by budgeting for training sessions or exploring ways to ensure that the competencies exist within the organization.

The board members also need to be aware of the basics that are required to have an effective HR management structure. This is because many of these local NGOs are small and do not have a human resource department. This is a role that board members need to take up especially where the organization is still growing.

According to John Adair $(2011: 96)^{10}$, he states that leaders provide an environment in which people can give their best hence creativity and innovations emerge. Local NGO leaders will need to proactively manage their human resource operations so as to sustain high staff performance over time.

\subsection{Develop and Implement Staff Performance Management System}

Organizational success comes from employees' total commitment to the organizational mission, goals, objectives, and values. It is the task of the management to induce and encourage that commitment.

Many organization face the challenge of having unmotivated employees whose poor performance affects the growth and survival of the organization.

Introduction of performance based incentives (monetary or non monetary forms), within local NGOs will go a long way to boost employee motivation.

\subsection{Develop Management/Leadership Succession Plans}

Planning for future management and leadership needs is linked to strategic focus of the organization. This is because of the dynamics of an aging workforce that is approaching retirement and transition of management to other organizations.

This involves identifying employees within an organization who have the capacity to take up key strategic

\footnotetext{
10 Adair John Eric (2011) The John Adair Lexicon of leadership.The definitive guide to leadership skills and knowledge. London. Kogan Page
}

positions that may fall vacant or may be created in the future. Some components of planning include: replacement planning, identify high-Potential employee, assessment of employee input and development of programs to build specific competency requirements.

Organizations that target on leadership succession and development are more flexible in the event of an unforeseen leadership change, because they will have the staff capacity to fill leadership vacancies.

Organizations must further consider ways to fill the gap by identifying as many options as possible to reduce the risk of strategic failure through integration of leadership development into the organization's overall strategic plan.

\subsection{Developing a HR Risk Management Plan}

Human resource engagement and management poses risks to local NGOs. It is therefore important for an organization to identify the HR risk factors and develop mechanisms to minimize the sources of risks to avoid costly lawsuits brought on by federal and state organs or employees.

Some NGOs are sometimes caught unawares on some legal contractual obligations as they develop contracts for employees and other risks that occur as a result of engaging staff in an organization.

\subsection{Outsourcing HR Functions}

Local NGOs that are small and lack the adequate funds to have a HR unit and find the different HR functions intensive and complex to manage from within can consider outsourcing.

Some key HR functions that can be outsourced may include; development of organizational policies and practices, career development, staff counseling, recruitment and selection.

This is especially important for local NGOs whose size is not too large to warrant having an internal HR team.

\subsection{Undertake Annual Organizational Knowledge Matrix Exercise}

This involves identification of key competencies for jobs required in the organization and assessing what is available or lacking among the staff.

This exercise will assist the local NGO management identify the competencies and skills that exist and the ones lacking. This will also encourage peer to peer learning among organizational individuals and help to avoid relying on one person who has "all" the skills.

This exercise is useful because organization strategies and approaches to project implementation change and evolve overtime. This will reduce instability in program implementation when staff transition as competencies will be periodically monitored and developed within the organization. 


\subsection{Conducting Periodic Organizational HR Assessments}

A periodic HR assessment will measure the effectiveness of an organization's HR management practices and ensure legal compliance. This will help improve, established HR documentation practices, identify strengths and weaknesses in staff appraisals and other HR practices.

An audit will improve HR practices within the organization especially where they may not have an HR unit or manager.

Organizations can set aside a budget to support this exercise just as they set aside money to conduct financial audits. Those who are being supported with institutional or capacity development should be proactive to negotiate for funds to undertake such an assessment.

Local NGOs need to regularly assess their organization HR management practices and regulations to protect the organization and its employee's best interests.

\subsection{Develop Strong Internal Organization Culture}

The aim is to provide employees with a conducive working environment. A strong organizational culture can be a great foundation for motivation and commitment among the employees. Where a strong and cohesive organization culture exists, core values are widely shared and employees identify themselves with their organization.

This can help minimize staff turnover that occur due to dissatisfaction among staff with organization's management practices.

\section{Conclusion}

The market environment for competant and skilled personnel is becoming increasingly competitive and costly.

The constant pressure for change has forced some local NGOs to realize that events within and externally affect their performance and survival. Local NGOs need to be aware that competent employees together with effective HR systems and practices are factors essential for securing sustainable competitive advantage in their market space or niche.

This requires local NGOs to be proactive in continuously seeking to improve their human resource management practices. Adoption of organizational development process can support local NGOs develop strategies that introduce planned and systematic HR management practices.

Organizational systems, processes and activities are integrated and synergized through a strong organizational culture.A crucial task for local NGO leadership is to evaluate the extent to which organizational culture ensures the strategic integration and adoption of human resource practices to make sure employee potential is harnessed and developed for the benefit of both the individual and organisation.

Donor agencies and governments are an important part in the local NGOs lifecycle as many organizations receive support from the two institutions to undertake development at community level. There is need for donor and government agencies to become more sensitive and pro-active in understanding the human resource challenges of partner implementing organisations and offer more support to build capacity in HR management in addition to providing funds and registration of the organizations.

\section{Acknowledgements}

I would like to appreciate the invaluable support I received from my University advisor Dr Valcin and the university team.

\section{References}

[1] Adair John Eric (2011) The John Adair Lexicon of leadership The definitive guide to leadership skills and knowledge .London. Kogan Page

[2] Armstrong Michael (2008) Strategic Human Resource Management: A guide to action. London. Kogan Page.

[3] Armstrong Michael (2011), Armstrong's handbook of strategic HRM. $5^{\text {th }}$ edition, London, Kogan Page.

[4] Armstrong Michael (2012), Armstrong's Handbook of Human Resource Management practice.(12 $2^{\text {th }}$ edition)UK. Ashford Colour Press.

[5] Brock, Meagan and Buckley M. Ronald,(2013) Human resource functioning in an information soceity. Practical suggestions and future implications. Public personnel Management (serial online) June 2013;42(2)272-280.

[6] Dartey- Baah, Kwasi,(2010) Technology transfer and Human resource constraints and challenges .A note to developing world. Academic Leadership (15337812) Volume 8,Issue 1

[7] Ekta Srivastava, Dr. Nisha Agarwal (2012) The Emerging Challenges in HRM International Journal of scientific \& technology research volume 1 issue 6,July 2012.

[8] Fottler, Myron\& Fried, Bruce (2008) Human resources in health care: Managing for success. Health Adminstration Press.

[9] HR focus: Turnover, globalization among emerging challenges facing human resource. (September 2011):88(9)10-11.

[10] Ishan Dantanarayana, (2014) Global best practices in HR. The Sunday times online. accessed on 23/4/2014. www.sundaytimes.lk/080615/FinancialTimes/ft310.html

[11] Josphat Stephen Itika (2011) Fundamentals of HRM: Emerging experiences from Africa: African studies University of Groningen /Mzumbe University African Public Adminstration and Management Series, volume 2

[12] Khavul, Susanna; Benson, George S.; and Datta, Deepak K. (2009) "HUMAN RESOURCE MANAGEMENT AND INTERNATIONAL NEW VENTURES FROM EMERGING MARKETS," Frontiers of Entrepreneurship Research: Vol. 29: Iss. 18, Article 1. Available at:http://digitalknowledge.babson.edu/fer/vol29/iss18/1.acce sed on $23 / 4 / 2014$ 
[13] Kim, Hyondong, Sung-Choon, Kang (2013), Strategic HR functions and firm performance: The moderating effects of high involvement work practices. Asia Pacific Journal of Management, March 2013, Volume 30,Issue 1p(91-113)

[14] McCann Joseph (2012) Focus on global Human Resource challenges: People and Strategy (serial online) April 2012;35(2):3.

[15] McConnell John H (2011) Auditing your Human resource department: A step by step guide to assessing the key areas of your program. ( $2^{\text {nd }}$ edition) New York. American Management Association.

[16] Pankaj Kumar (2011) Emerging challenges in HRM. http://www.slideshare.net/birubiru/emerging-challenes-in-hr $\mathrm{m}-7623957$

[17] Savage Grant, Khatri Naresh, Foller Myron D(2010) Strategic HRM in health care in advances in health care management.( $1^{\text {st }}$ edition)Bingley, UK, Emerald.

[18] Shilpika Pandey (2012)Future trends in HRM ,VSRD International journal of business and management research Vol 2,No 12,Dec 2012.www.vrsdjournals.com
[19] Shiny Nair, (2009) Emerging trends in Human resource managment.www.articlebase.com/humanresources/emerging trends in HRM. Retrieved 10/4/2014

[20] Sree Rama Rao (2010), Factors Influencing the Personnel Function. http://www.citeman.com/12486-factors-influencing-the-pers onnel function.html\#ixzz2zi4nhTqp

[21] Stahl G. Bjorkmann (2006) Handbook of research in International HRM Cheltenham, UK:E. Elger Publication

[22] Stanley Vincent, Albin Joseph (2013) Challenges for human resource experts in Global scenerio. International Journal of advancement in Research and Technology. Vol 2, Issue 4,April 2013.SciResPub.

[23] Ullah, Ifran and Yasmin Robina,(2013) The influence of human resource practices on internal customer satisfaction and organization effectives. Journal of Internet Banking and Commerce. August 2013, Volume 18,Issue 2:1-28.

[24] Wahyudi Eric and Sung Min Park (2014) Unceiling the value creation process of EHRM. An Indonesian case. Public personnel management (serial online) March 2014:43(1)83-117. 